\title{
A ten-year comparative study of cardiovascular disease publications, health and socioeconomic indicators between European countries
}

\author{
Domagoj Markovic ${ }^{1, \star}$, Josip Lukenda ${ }^{2}$, Visnja Kokic ${ }^{3}$, Petra Simac ${ }^{3}$, \\ Piero Marin Zivkovic ${ }^{3}$, Ingrid Prkacin ${ }^{4}$, Viktor Culic ${ }^{1}$
}

${ }^{1}$ Clinic for heart and cardiovascular diseases, University hospital of Split, Croatia

${ }^{2}$ Clinic for internal medicine, Clinical hospital "Sveti Duh", Zagreb, Croatia

${ }^{3}$ Clinic for internal medicine, University hospital of Split, Croatia

${ }^{4}$ Department of internal medicine, Clinical hospital "Merkur", Zagreb, Croatia

\section{*Correspondence}

markovic.domagoj@gmail.com

(Domagoj Markovic)

\begin{abstract}
The aim of this study was to investigate and compare gross domestic product (GDP) per capita, the number of physicians per one million inhabitants, the number of cardiovascular disease (CVD) publications, standardized death rate (SDR) from ischemic heart disease (IHD) and CVD per 100000 inhabitants per year between European countries. GDP per capita from the Eurostat database served as the socioeconomic indicator, whereas human resources in medicine were reported as the number of physicians per million inhabitants. PubMed was searched for CVD publications published between 2005 and 2014 for each country. The rate per million inhabitants and proportions of CVD publications in the MEDLINE database were calculated. Results showed that although Croatia was the only country with stagnation in GDP per capita and with a lower rate of physicians than Austria $(P=0.007)$ and the Czech Republic $(P=0.005)$, Croatia had a lower SDR from IHD and CVD than the European region $(P=0.05, P=0.021$; respectively), and had a continuous decrease in the average annual growth rate of IHD and CVD $(-2.36 \%,-3.81 \%$; respectively). In conclusion our study showed that Croatia, despite being the only country with the stagnation of GDP per capita and a relatively low rate of physicians, had a SDR from IHD and CVD that was lower than in the European region which continuously decreased during the study period.
\end{abstract}

\section{Keywords}

Cardiovascular disease; Croatia; Gross domestic product; Publications; Health status indicators

\section{Introduction}

Cardiovascular disease (CVD) is the main cause of death in developed countries worldwide. It is an important cause of disability and a source of increased economic and social burden for society. The World Health Organization estimated that CVD led to 17.9 million deaths globally which is $31 \%$ of all deaths annually [1-3]. The ratio is even larger in Europe, where CVD is responsible for more than 4 million deaths or $46 \%$ of all deaths annually [ 4 ].

CVD is also a major contributor to inequalities in the health status of inhabitants in Europe. In comparison to Western Europe, Eastern Europe traditionally had a higher overall, and especially CVD related mortality, but considerable differences could be seen among individual Eastern European countries [5-7]. One of the reasons for the difference between countries in ischemic heart disease (IHD) and CVD mortality is the variance in the economic status of each country. An increase in the gross domestic product (GDP) per capita strongly correlates with a decrease in the IHD and CVD mortality [8].
The number of scientific publications published in a country is a good indicator of scientific development [9]. Every country has a different approach to science and investments in science, but wealthier countries generally tend to invest more in science than poorer countries. Economically more prosperous countries, with a larger GDP, create more opportunities for research and are scientifically more successful $[10,11]$. In the period from 1991 to 2004, there were advances in cardiovascular medicine in Croatia that were not reflected in scientific productivity [12]. Also, a significant progress in the clinical practice, which was measured by an increase in the number of coronary angiograms by $8.5 \%$ and percutaneous interventions by $15 \%$, has been recently reported [13]. Publications directly influence decisions made by physicians in their clinical practice [14]. Advancements in clinical practice are usually followed by an increase in clinical trials that ultimately result in increased scientific publications.

In order to explore country-specific differences in clinical practice related to cardiovascular medicine and scientific productivity, our primary goal was to determine the GDP per 
capita, the number of physicians per one million inhabitants, standardized death rate (SDR) from IHD and CVD per 100000 inhabitants per year in population in Croatia, and then to compare the same parameters for Slovenia, Hungary, the Czech Republic, Poland, the Slovak Republic and Austria between 2005 and 2014. Our secondary goal was to investigate whether progress in clinical practice in Croatia had been followed by an increase in the number of CVD publications.

\section{Materials and methods}

Lukenda et al. reported intriguing results in the period from 1991 until 2004 so we used similar methods for selected countries in our study to explore and update these findings [12]. We searched the MEDLINE database using PubMed to identify publications on CVD from 2005 to 2014 [15]. The term "cardiovascular disease" was entered as the Medical Subject Headings (MeSH) descriptor, and country names (Croatia, Slovenia, Hungary, Czech Republic, Slovak Republic, Poland, and Austria) were entered as the descriptor with (AD) abbreviation to obtain publications with the author's affiliation from each of these countries. Dates from January 1 until December 31 were entered for every year between 2005 and 2014 in the "Publication date" field.

The number of CVD publications from each country was expressed as the publication rate (number of CVD publications per 1,000,000 inhabitants per year) and a proportion of CVD publications in the total number of publications from that particular country in the MEDLINE database.

Data on GDP per capita and population size on January 1 in the selected years were retrieved from the Eurostat database [16]. GDP per capita is expressed in thousands of euros per inhabitant per year. Human resources in medicine (number of physicians per 100,000 inhabitants per year) and the cardiovascular health indicators (SDR for both sexes aged 0-64 from IHD and CVD) for the 2005-2014 period for each country were obtained from the "European health for all database" [17]. This database allows the analysis of trends and international comparisons for a wide range of health indicators to support the formulation and monitoring of health policy at national and international levels. Data with the number of physicians for the Slovak Republic were available only for the year 2007 so this country was excluded from this particular analysis. Data for SDR from IHD and CVD for Slovenia were available in the same database from 2005 to 2010; data from 2011 to 2014 were obtained from the National Institute of Public Health of the Republic of Slovenia [18]. SDR is the age-standardized death rate calculated using the direct method and standard European population structure which has allowed an unbiased comparison between countries, serving as health indicators and providing estimates of the cardiovascular health of the population.

\subsection{Statistical analysis}

Data were entered into the electronic spreadsheet and statistical analysis was performed using the Statistica 10 software package (StatSoft Inc., Tulsa, OK, USA). To investigate possible differences in GDP per capita, the number of publications per one million inhabitants per year, number of CVD publications, number of physicians, and the SDR from IHD and CVD between selected countries, we used the chi-square test with the Yates correction. For each parameter, the median of all values was calculated. In the chi-square test, the number of years above and below the median was entered for every country and the parameter of interest and used for comparison between each of the countries. If the value of any parameter in the year was identical to the value of the median, the value was placed above the median. Statistical significance was set at $P<0.05$.

To compare temporal changes in GDP per capita, the number of publications per one million inhabitants per year, the number of CVD publications, number of physicians, and the SDR from IHD and CVD between the countries, we used the chain index. The chain index is the most widely used parameter in economic research which compares the value of the investigated parameter in the selected year with the value from the preceding year. The geometric mean of all chain indexes for each parameter from each country was used for calculation of the average annual growth rate. The geometric mean has been suggested as the most descriptive and reliable method for calculating average annual growth rate [19].

\section{Results}

Croatia had a significantly lower GDP per capita than the Czech Republic, Austria, Slovenia (chi-square $=16.22, P<$ $0.001)$ and the Slovak Republic (chi-square $=4.26, P=0.039$ ) (Table 1). Austria was the leading country for GDP per capita with an average of 35.4 thousand euros (Fig. 1). Croatia had a relatively constant GDP per capita of 10.2 thousand euros in 2005 and in 2014. Croatia had the lowest average annual growth rate of GDP per capita and it was the only country with a GDP stagnation (Table 2).

Austria had the greatest number of CVD publications per million inhabitants yearly with an average of 55.9 and the Slovak Republic had the least publications with the average of 8.1 (Fig. 2). Slovenia and Croatia had the lowest increase in the average annual growth rate in the number of CVD publications (2.21\%, 6.18\%; respectively) (Table 2$)$.

No difference was observed in the number of CVD publications in the total number of publications between Croatia and other countries (Table 1). There was a decline in the average annual growth rate in the number of CVD publications in the total number of publications in most countries, except in the Czech Republic and Hungary (Table 2) (Fig. 3).

Croatia had a lower total number of physicians per one million inhabitants compared to Austria (chi-square $=7.912$, $P=0.005$ ) and the Czech Republic (chi-square $=7.193, P=$ 0.007 ) (Table 1). All countries had an increase in the average annual growth rate and Croatia, with $2.56 \%$, had the highest (Fig. 4) (Table 2).

Croatia had a lower SDR from IHD than Hungary and the Slovak Republic (chi-square $=4.267, P=0.039$ ) but it was higher than in Slovenia and Austria (chi-square $=4.267, P=$ 0.039) (Table 1). Croatia had a borderline lower SDR from IHD than the European region (chi-square $=3.801, P=0.05$ ). Poland had the greatest decrease of average annual growth rate from IHD (-5.04\%) (Fig. 5) (Table 2). 


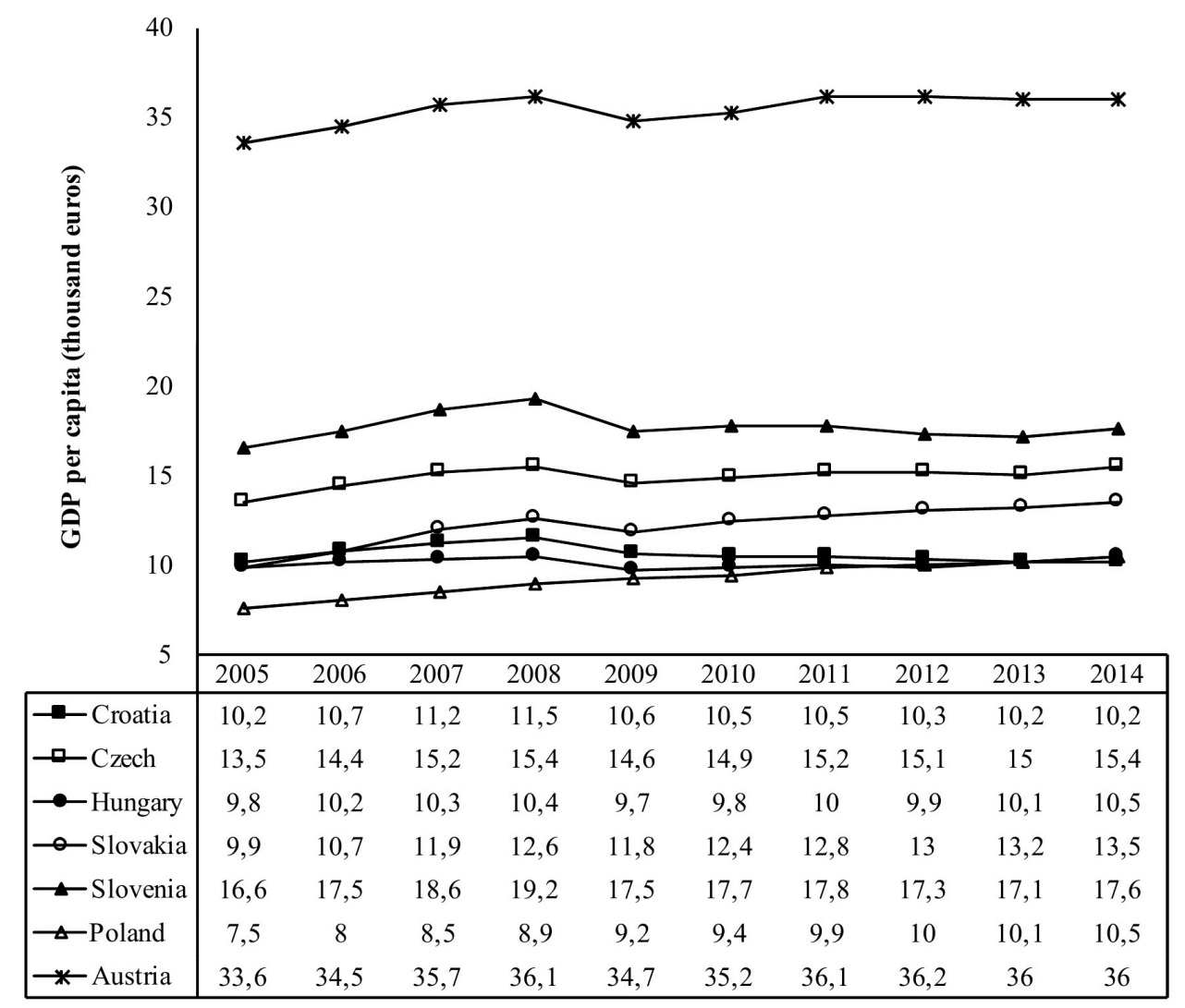

F I G U RE 1. GDP per capita in euros in period between 2005 and 2014. Legend: GDP, gross domestic product.

TA B L E 1. Calculated medians for investigated parameters and number of years above median for each country.

\begin{tabular}{|c|c|c|c|c|c|c|}
\hline & $\begin{array}{l}\text { GDP* per capita } \\
\text { (thousand euros) }\end{array}$ & $\begin{array}{l}\text { No. of } \mathrm{CVD}^{\dagger} \text { pub- } \\
\text { lications/million } \\
\text { inhabitants }\end{array}$ & $\begin{array}{c}\% \text { of } \mathrm{CVD}^{\dagger} \\
\text { publications in } \\
\text { total number }\end{array}$ & $\begin{array}{c}\text { No. of } \\
\text { physicians/100 } \\
000 \text { inhabitants }\end{array}$ & $\begin{array}{c}\mathrm{SDR}^{\ddagger} \text { from } \\
\mathrm{IHD}^{\S} / 100000 \\
\text { inhabitants }\end{array}$ & $\begin{array}{c}\mathrm{SDR}^{\ddagger} \text { from } \\
\mathrm{CVD}^{\dagger} / 100000 \\
\text { inhabitants }\end{array}$ \\
\hline Median & 12.5 & 20.5 & 8.2 & 295.8 & 31.5 & 71 \\
\hline Croatia & $0^{\| \boldsymbol{\Phi}}$ & 6 & 4 & $3 * *$ & $5^{\dagger \dagger}$ & $4^{\ddagger \ddagger}$ \\
\hline Czech Republic & 10 & 6 & 2 & 9 & 3 & 1 \\
\hline Hungary & 0 & 1 & 3 & 7 & 10 & 10 \\
\hline Slovenia & 10 & 10 & 3 & 0 & 0 & 0 \\
\hline Slovak Republic & 5 & 0 & 8 & - & 10 & 7 \\
\hline Poland & 0 & 2 & 9 & 0 & 3 & 9 \\
\hline Austria & 10 & 10 & 7 & 10 & 0 & 0 \\
\hline European Region & - & - & - & 6 & 9 & 9 \\
\hline
\end{tabular}

Legend: * GDP, gross domestic product; ${ }^{\dagger} C V D$, cardiovascular disease; ${ }^{\ddagger} S D R$, standardized death rate; ${ }^{\S} I H D$, ischemic heart disease; $\| P<0.001$ when compared to Czech Republic, Slovenia, Austria; ${ }^{\mathbb{I}} P<0.05$ when compared to Slovak Republic; ${ }^{* *} P<0.05$ when compared to Czech Republic and Austria; ${ }^{\dagger \dagger} P<0.05$ when compared to Hungary, Slovak

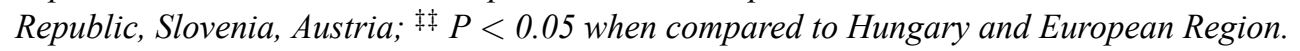

Croatia had a lower SDR from CVD than Hungary (chisquare $=5.592, P=0.015$ ) and the European region (chi-square $=5.36, P=0.021)($ Table 1). Austria, with 30.5 per 100000 inhabitants, had the lowest average SDR from CVD (Fig. 6). All countries had a decrease in the average annual growth rate from CVD; Slovenia had the greatest decrease $(-5.77 \%)$ (Table 2).

\section{Discussion}

To the best of our knowledge, this study is the first to investigate GDP per capita, number of CVD publications, number of physicians, SDR for IHD and CVD for Croatia compared to neighboring countries between 2005-2014.

CVD is the leading cause of morbidity and mortality globally $[1,4]$. Several CVD risk factors, such as a higher BMI, systolic blood pressure, total cholesterol, as well as invest- 


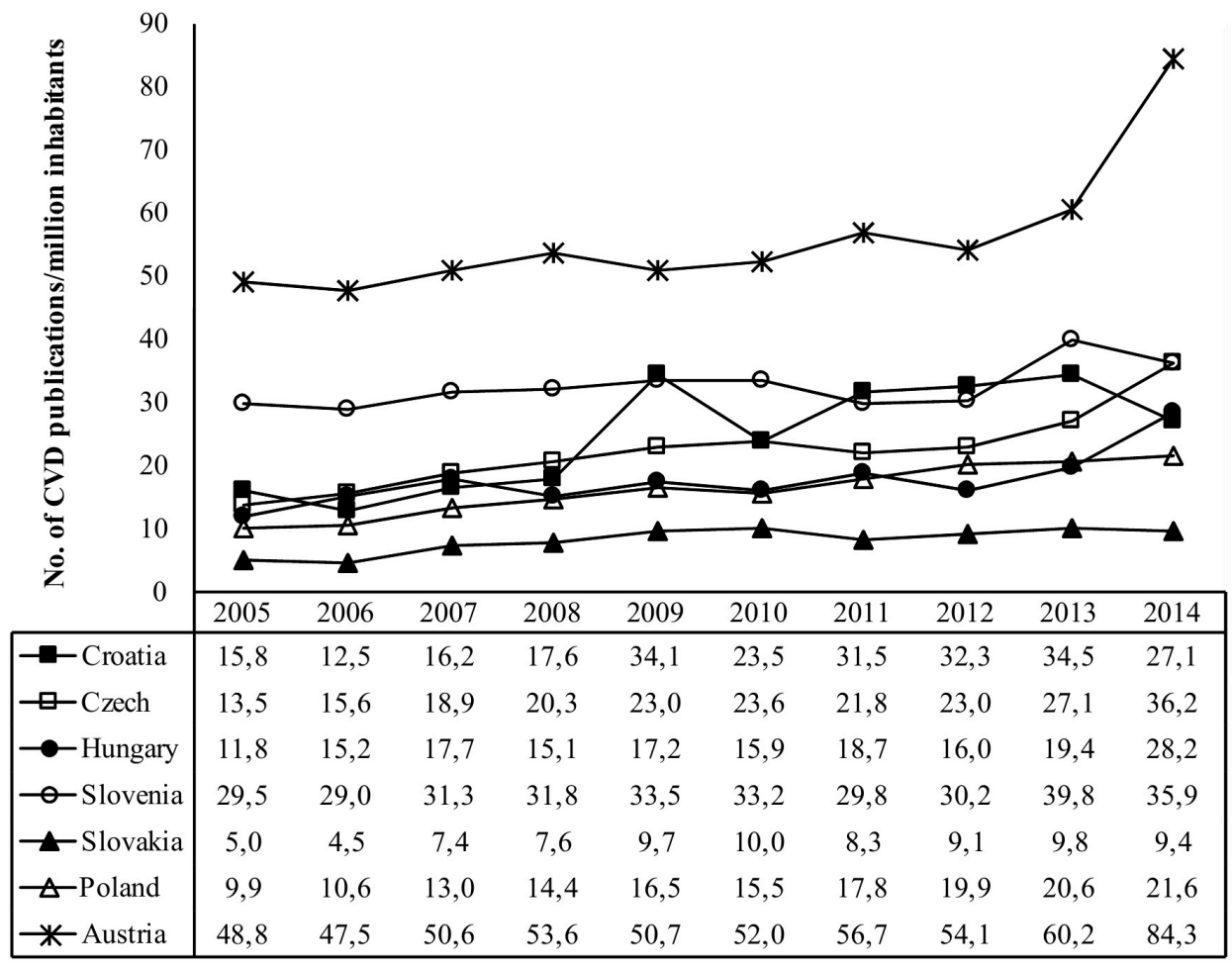

F I G U R E 2. Number of CVD publications per million inhabitants per year. Legend: CVD, cardiovascular diseases.

TA B L E 2. Average annual growth rate for each country between 2005 and 2014.

$\begin{array}{lccccccc} & \begin{array}{c}\text { GDP* per capita } \\ \text { (thousand euros) }\end{array} & \begin{array}{c}\text { No. of CVD pub- } \\ \text { lications/million } \\ \text { inhabitants }\end{array} & \begin{array}{c}\text { \% of CVD } \\ \text { publications in } \\ \text { total number }\end{array} & \begin{array}{c}\text { No. of } \\ \text { physicians/100 } \\ 000 \text { inhabitants }\end{array} & \begin{array}{c}\mathrm{SDR}^{\ddagger} \text { from } \\ \mathrm{IHD}^{\S} / 100000 \\ \text { inhabitants }\end{array} & \begin{array}{c}\mathrm{SDR}^{\ddagger} \text { from } \\ \mathrm{CVD}^{\dagger} / 100 \\ \text { inhabitants }\end{array} \\ \text { Croatia } & 0.00 & 6.18 & -0.72 & 2.56 & -2.36 & -3.81 \\ \text { Czech Republic } & 1.47 & 11.58 & 0.61 & 0.46 & -3.06 & -3.75 \\ \text { Hungary } & 0.77 & 10.16 & 2.16 & 2 & -3.95 & -3.58 \\ \text { Slovenia } & 0.65 & 2.21 & -6.06 & 1.87 & -2.42 & -5.77 \\ \text { Slovak Republic } & 3.51 & 7.27 & -2.86 & - & -3.18 & -4.36 \\ \text { Poland } & 3.81 & 9.06 & -1.57 & 0.85 & -5.04 & -2.61 \\ \text { Austria } & 0.77 & 6.26 & -3.08 & 1.75 & -3.35 & -3.15 \\ \text { European Region } & - & - & - & 1.49 & -4.15 & -3.99\end{array}$

Legend: * GDP, gross domestic product; ${ }^{\dagger}$ CVD, cardiovascular disease; ${ }^{\ddagger}$ SDR, standardized death rate; ${ }^{\S}$ IHD, ischemic heart disease.

ments in health care, are directly associated with the GDP per capita [20-22]. Increased GDP per capita is directly associated with decreased IHD and CVD mortality [8, 23] probably via primary prevention of CVD risk factors. Countries with an annual increase in the GDP per capita have a more developed primary health care system which is associated with lower rates of CVD and all-cause mortality [24]. Croatia was the only country among those investigated with a stagnation in the GDP per capita. Surprisingly, the SDR from IHD and CVD was among the lowest, lower than the European region, which was associated with a continuous decrease during the study period. Similar results of lower CVD mortality were found in the Southern European countries when compared to Northern Europe [25]. There was an increase in the SDR from IHD worldwide in the period from 1990 until 2010. One of possible explanations was the underuse of daily standard oral medications [26]. Our results showed that all the observed countries and the European region showed a decrease of SDR from IHD and CVD in the observed period.

Croatia, Poland, and Slovenia had fewer physicians compared to other countries. Recent studies suggest that the ratio of physicians per capita is a critical factor for SDR; i.e. the higher the ratio, the lower the $\operatorname{SDR}[27,28]$. In addition, a higher proportion of physicians and nurses is related to a higher quality of care and a lower incidence of adverse events [29].

Although Croatia was the only country among those investigated with a stagnation in the GDP per capita and had a relatively lower rate of physicians the SDR from IHD and CVD was lower than in the European region. The lower IHD and CVD mortality in Croatia could be partially due to the use of 


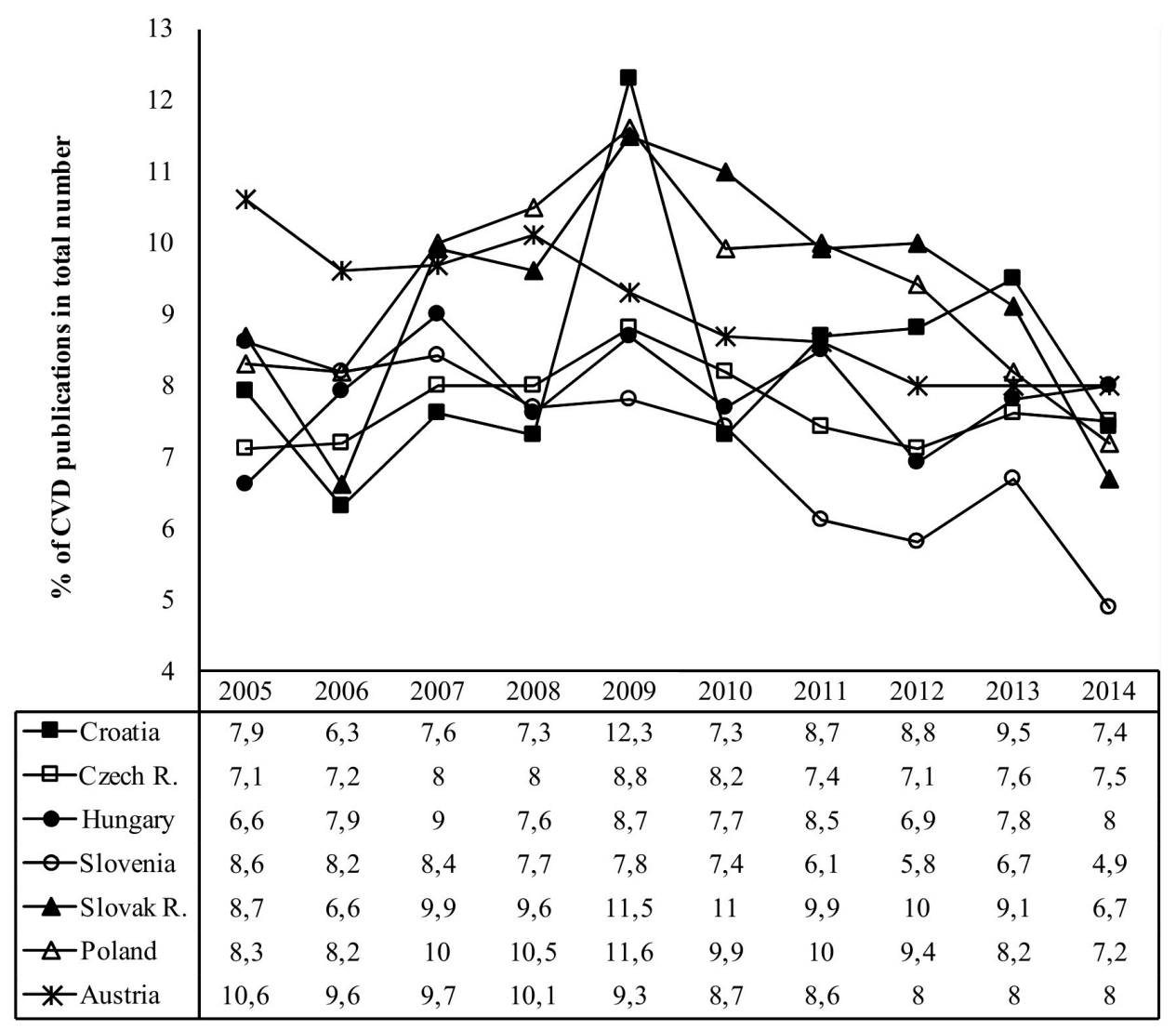

F I G U R E 3. Percentage of CVD publications in overall MEDLINE database. Legend: CVD, cardiovascular disease.

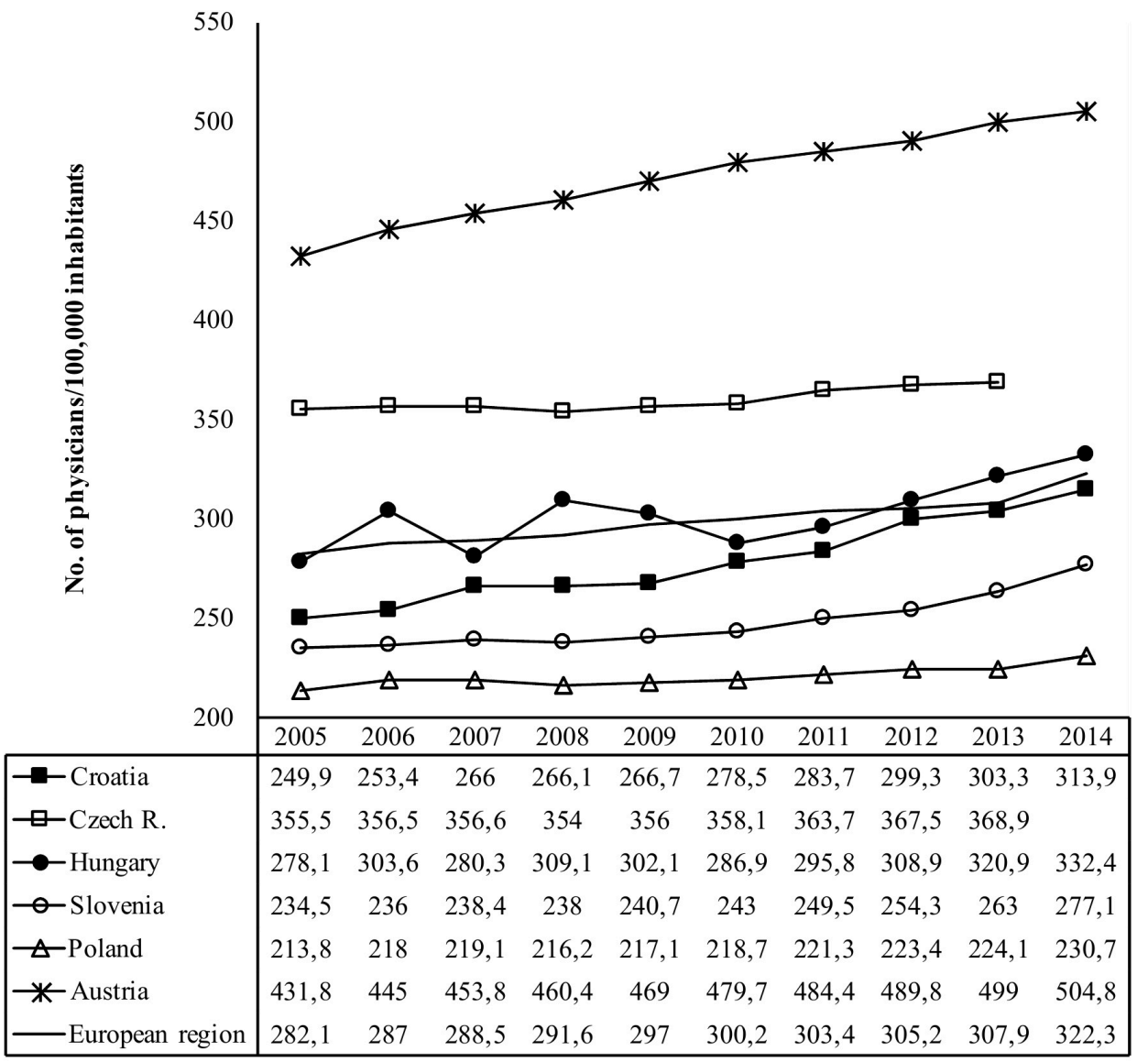

F I G U R E 4. Number of physicians per 100000 inhabitants per year. 


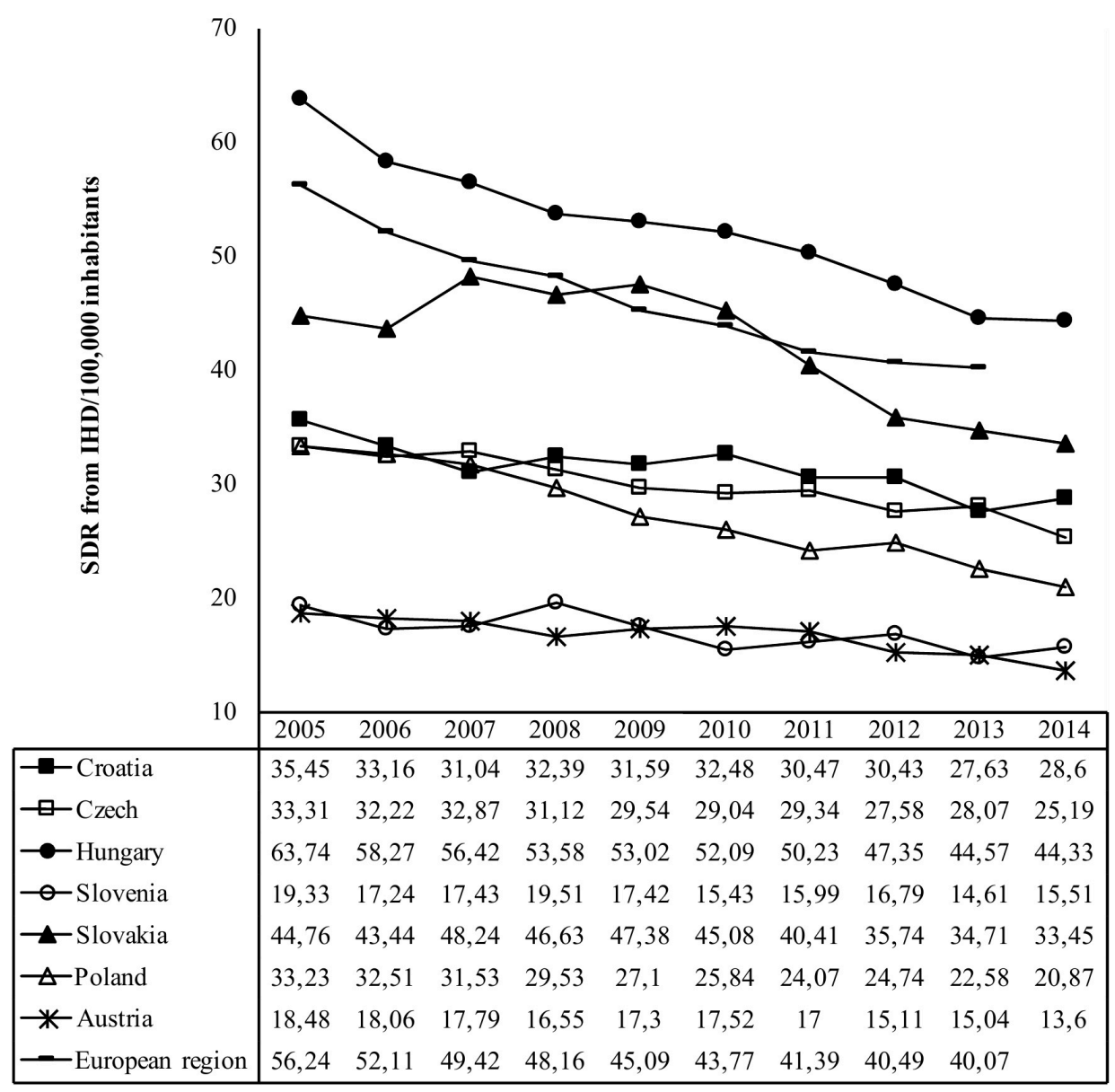

F I G U RE 5. Standardized death rate from IHD per 100000 inhabitants per year in population under age of 64 years. Legend: IHD, ischemic heart disease; SDR, standardized death rate.

the Mediterranean diet which has been shown to have a CVD protective role [30,31]. Also, the Mediterranean climate with its mild winters and summers could have a beneficial impact on overall health leading to a lower mortality [32]. Despite the stagnation in the GDP per capita, Croatia continuously advances and invests in primary prevention as per the European Society of Cardiology guidelines [33]. Recent studies suggest that the health care system in Croatia is very good despite the relatively low amount of investments when compared to Western European countries [34].

Our study found that scientific research in Croatia did not correlate with the progress in clinical practice in the period between 2005 and 2014. Croatia and Slovenia had the lowest increase in the average annual growth rate in CVD publications among all investigated countries. Lukenda et al. reported similar findings in which Croatia had the lowest rate of CVD publications in the period between 1991 and 2004 [12]. Recent studies suggest that Croatia has the lowest number of registered trials among countries from Central and Eastern Europe [35]. We suspect that the stagnation in the GDP per capita in Croatia has already affected the number of physicians and the average annual growth rate in CVD publications but not yet the SDR from IHD and CVD. Our assumption is that over a longer time period these factors would also be affected.

Our study had several limitations. First, data on the number of physicians for the Slovak Republic were lacking in the searched databases and were available only for 2007. Second, we evaluated cardiovascular scientific output only with the number of the CVD publications and with no evaluation of the quality of scientific publications.

\section{Conclusions}

We conclude that in Croatia, despite being the only country with stagnation of GDP per capita and a relatively low rate of physicians, SDR from IHD and CVD was lower than in the European region with a continuous decrease, possibly due to the Mediterranean diet and a mild climate. Cardiovascular scientific publications in Croatia did not follow the progress that was observed in clinical practice during this time period.

\section{AUTHOR CONTRIBUTIONS}

Domagoj Markovic, Josip Lukenda and Viktor Culic designed the study. Domagoj Markovic, Visnja Kokic and Petra Simac collected the data. Domagoj Markovic and Piero Marin Zivkovic analyzed the data. Domagoj Markovic and Ingrid Prkacin analyzed the results and drafted the manuscript. Domagoj Markovic, Josip Lukenda, Viktor Culic, Visnja Kokic, Petra Simac, Piero Marin Zivkovic and Ingrid Prkacin read and approved the last version of the manuscript. 


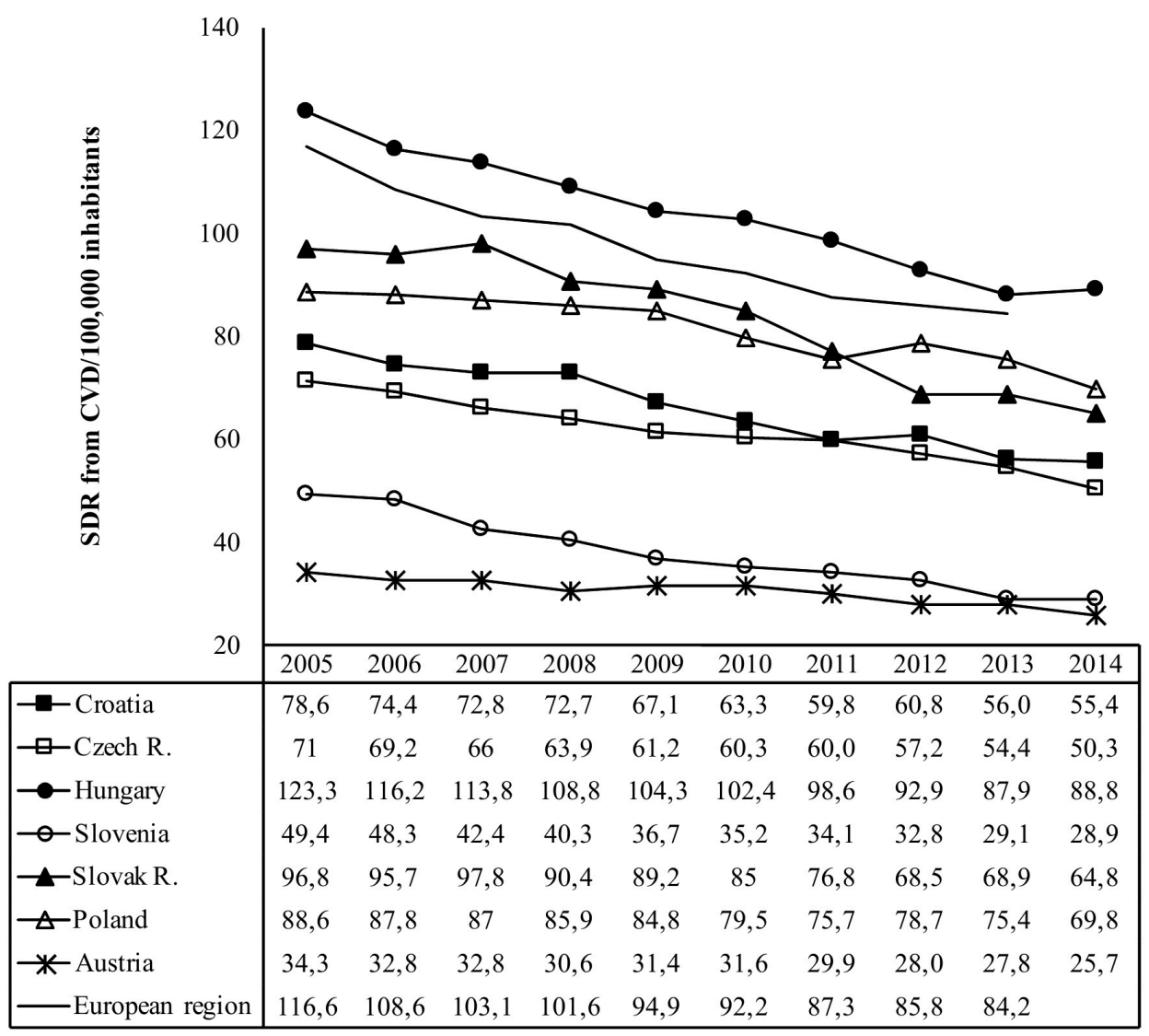

F I G U RE 6. Standardized death rate from CVD per 100000 inhabitants per year in population under age of 64 years. Legend: CVD, cardiovascular disease; SDR, standardized death rate.

\section{ACKNOWLEDGMENT}

Thanks to all the peer reviewers and editors for their opinions and suggestions.

\section{FUNDING}

This research received no grant from any funding agency in the public, commercial, or not for profit sectors.

\section{CONFLICT OF INTEREST}

The authors declare that there is no conflict of interest regarding the publication of this article.

\section{REFERENCES}

[1] Lozano R, Naghavi M, Foreman K, Lim S, Shibuya K, Aboyans V, et al. Global and regional mortality from 235 causes of death for 20 age groups in 1990 and 2010: a systematic analysis for the Global Burden of Disease Study 2010. The Lancet. 2012; 380: 2095-2128.

[2] Joseph P, Leong D, McKee M, Anand SS, Schwalm J, Teo K, et al. Reducing the global burden of cardiovascular disease, part 1. Circulation Research. 2017; 121: 677-694.

[3] World Health Organization. Cardiovascular diseases (CVDs). 2017. Available at: https://ww.who.int/news-room/fact-sheets/ detail/cardiovascular-diseases-(cvds) (Accessed: 08 January 2021).

[4] Nichols M, Townsend N, Scarborough P, Rayner M. Cardiovascular disease in Europe 2014: epidemiological update. European Heart Journal. 2014; 35: 2950-2959.
[5] Uemura K, Pisa Z. Trends in cardiovascular disease mortality in industrialized countries since 1950. World Health Statistics Quarterly. Rapport Trimestriel De Statistiques Sanitaires Mondiales. 1988; 41: 155178.

[6] Bobak M, Marmot M. East-West mortality divide and its potential explanations: proposed research agenda. British Medical Journal. 1996; 312: 421-425.

[7] Forster DP, Józan P. Health in Eastern Europe. The Lancet. 1990; 335: 458-460.

[8] Soares GP, Brum JD, Oliveira GMMD, Klein CH, Silva NASE. Evolution of socioeconomic indicators and cardiovascular mortality in three Brazilian States. Arquivos Brasileiros De Cardiologia. 2013; 100 : 147-156.

[9] Takei N. Geography of biomedical publications. The Lancet. 1999; 354 516-517.

[10] Jurajda S̆, Kozubek S, Münich D, Škoda S. Scientific publication performance in post-communist countries: still lagging far behind. Scientometrics. 2017; 112: 315-328.

[11] Tucker-Drob EM, Cheung AK, Briley DA. Gross domestic product, science interest, and science achievement: a person $\times$ nation interaction. Psychological Science. 2014; 25: 2047-2057.

[12] Lukenda J, Kolaric B, Kolcic I, Pazur V, Biloglav Z. Cardiovascular diseases in Croatia and other transitional countries: comparative study of publications, clinical interventions, and burden of disease. Croatian Medical Journal. 2005; 46: 865-874.

[13] Lukenda J, Starcevic B, Delic Brkljacic D, Biloglav Z. An analysis of cardiologic interventional procedures in Croatia between 2010 and 2014: towards the establishment of a National Registry. Cardiologia Croatica. 2016; 11: 142-150.

[14] McKee M. Indicators of clinical performance. British Medical Journal. 1997; 315: 142-142.

[15] NCBI. PubMed. Available at: https://www.ncbi.nlm.nih.gov/ pubmed/ (Accessed: 15 February 2016). 
[16] European Union. Eurostat-Data. Available at: http://appsso. eurostat. ec. europa.eu/nui/submitViewTableAction.do (Accessed: 15 February 2016)

[17] World Health Organization. WHO Europe. Available at: http: //www . euro. who. int/en/home (Accessed: 15 September 2016).

[18] Nacionalni inštitut za javno zdravje. NIJZ. Available at: http: //www. nijz.si/ (Accessed: 15 September 2016).

[19] Chain Base Method. eMathZone. 2014. Available at: http: //ww . emathzone. com/tutorials/basic-statistics/chainbase-method.html (Accessed: 05 July 2017).

[20] Danaei G, Singh GM, Paciorek CJ, Lin JK, Cowan MJ, Finucane MM, et al. The global cardiovascular risk transition associations of four metabolic risk factors with national income, urbanization, and western diet in 1980 and 2008. Circulation. 2013; 127: 1493-1502.

[21] Fuchs VR. The gross domestic product and health care spending. The New England Journal of Medicine. 2013; 369: 107-109.

[22] Gheorghe A, Griffiths U, Murphy A, Legido-Quigley H, Lamptey P, Perel $\mathrm{P}$. The economic burden of cardiovascular disease and hypertension in low- and middle-income countries: a systematic review. BMC Public Health. 2018; 18: 975.

[23] Jacob JA. Greater health care spending may moderate recession's negative health effects. Journal of the American Medical Association. 2016; 315: 237-239.

[24] Macinko J, Starfield B, Shi L. The contribution of primary care systems to health outcomes within Organization for Economic Cooperation and Development (OECD) countries, 1970-1998. Health Services Research. 2003; 38: 831-865.

[25] Menotti A, Puddu PE. Coronary heart disease differences across Europe. Journal of Cardiovascular Medicine. 2013; 14: 767-772.

[26] Moran AE, Forouzanfar MH, Roth GA, Mensah GA, Ezzati M, Flaxman A, et al. The global burden of ischemic heart disease in 1990 and 2010: the Global Burden of Disease 2010 study. Circulation. 2014; 129: 14931501 .

[27] Jarman B, Gault S, Alves B, Hider A, Dolan S, Cook A, et al. Explaining differences in English hospital death rates using routinely collected data.
British Medical Journal. 1999; 318: 1515-1520.

[28] Chai K-C, Zhang Y-B, Chang K-C. Regional disparity of medical resources and its effect on mortality rates in china. Frontiers Public Health. 2020; 8: 8 .

[29] Kuhn EM, Hartz AJ, Gottlieb MS, Rimm AA. The relationship of hospital characteristics and the results of peer review in six large states. Medical Care. 1991; 29: 1028-1038.

[30] Anderson JJB, Nieman DC. Diet quality-the Greeks had it right! Nutrients. 2016; 8: 636.

[31] Guasch-Ferré M, Salas-Salvadó J, Ros E, Estruch R, Corella D, Fitó M, et al. The PREDIMED trial, Mediterranean diet and health outcomes: how strong is the evidence? Nutrition, Metabolism, and Cardiovascular Diseases. 2017; 27: 624-632.

[32] Medina-Ramon M, Schwartz J. Temperature, temperature extremes, and mortality: a study of acclimatisation and effect modification in 50 US cities. Occupational and Environmental Medicine. 2007; 64: 827-833.

[33] European Society of Cardiology. escardio. Available at: https: //www.escardio.org/Sub-specialty-communities/EuropeanAssociation-of-Preventive-Cardiology-(EAPC)/Advocacy/ Prevention-in-your-country/country-of-the-monthcroatia (Accessed: 01 December 2017).

[34] Džakula A, Sagan A, Pavić N, Lonćčarek K, Sekelj-Kauzlarić K. Croatia: health system review. Health Systems in Transition. 2014; 16: xvii-x162.

[35] Solic I, Stipcic A, Pavlicevic I, Marusic A. Transparency and public accessibility of clinical trial information in Croatia: how it affects patient participation in clinical trials. Biochemia Medica. 2017; 27: 259-269.

How to cite this article: Domagoj Markovic, Josip Lukenda, Visnja Kokic, Petra Simac, Piero Marin Zivkovic, Ingrid Prkacin, et al. A ten-year comparative study of cardiovascular disease publications, health and socioeconomic indicators between European countries. Signa Vitae. 2021;17(3):95-102. doi:10.22514/sv.2021.053. 